\title{
LÍNGUA INGLESA NO BRASIL, REFORMAS EDUCATIVAS E MÉTODOS DE ENSINO: ASPECTOS DE UMA TRAJETÓRIA DISCIPLINAR ${ }^{1}$
}

\author{
ENGLISH LANGUAGE IN BRAZIL, EDUCATIONAL REFORMS AND TEACHING \\ METHODS: ASPECTS OF A DISCIPLINE'S TRAJECTORY
}

\author{
(iD) Sofia Bocca \\ Mestranda em Educação pela PUCPR \\ Professora e tradutora de Língua Inglesa \\ Curitiba - Paraná - Brasil \\ sofia.bocca@hotmail.com
}

\begin{abstract}
Resumo: $\mathrm{O}$ presente artigo expõe brevemente a trajetória da língua inglesa como disciplina escolar no Brasil, para que possamos, assim, entender aspectos de sua inserção, suas características e finalidades no decorrer da história de sua inclusão em processos de escolarização. Por meio da pesquisa bibliográfica histórica, são expostos também aspectos de reformas ocorridas no âmbito educacional desde sua inserção nos programas e currículos brasileiros, bem como os diferentes métodos e abordagens concebidos para o seu ensino. Dessa forma, podemos observar que, por vezes, essa disciplina recebe importância no ambiente escolar e, em outras, é desprestigiada. Tudo indica que, mesmo decorrido tanto tempo, o ensino da língua sofre mudanças sutis, mas que não são capazes de causar mudanças efetivas no ensino.
\end{abstract}

Palavras-chave: Língua inglesa. Disciplinas escolares. Ensino-aprendizagem de línguas

\begin{abstract}
This article briefly exposes the trajectory of the English language as a school discipline in Brazil, so that we can understand aspects of its insertion, characteristics and purposes throughout the history of its inclusion in schooling processes. Through historical bibliographic research, aspects of reforms that have occurred in the educational field are also exposed since their insertion in Brazilian programs and curricula, as well as the different methods and approaches conceived for their teaching. Thus, we can observe that sometimes this discipline receives importance in the school environment and some other times it is undervalued. It seems that even after such a long time, language teaching undergoes subtle changes, but they are not capable of making effective changes in teaching and learning.
\end{abstract}

Keywords: English language. School subjects. Language teaching and learning 


\section{Introdução}

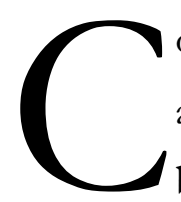

onsiderando as disciplinas escolares como objeto histórico, neste artigo apresento uma breve trajetória da disciplina de língua inglesa na escola brasileira, desde o século XIX até a contemporaneidade, com o objetivo de entender como ela foi implantada, inicialmente nos programas de ensino e depois, nos currículos. Assim, por se tratar de objeto histórico, a disciplina de Língua Inglesa é também um objeto cultural produzido em certo tempo e espaço históricos, ocupando lugar importante na cultura escolar, tendo em conta os interesses de grupos que a forjaram. Neste artigo, apresento a Língua Inglesa como disciplina enfocando dados político-históricos que influenciaram seu estabelecimento nas instituições escolares no Brasil.

Por ser a disciplina de Língua Inglesa um objeto cultural que dimensiona certas práticas no domínio da cultura escolar, ela demanda uma abordagem histórica diferenciada; nesse caso, abordagem da História Cultural, pois, por meio dela, historiadores dispõem de perspectivas variadas para estudar e entender a História. Essa perspectiva historiográfica foi amplamente aceita e legitimada no século XX, cuja vertente francesa tem Roger Chartier como um de seus maiores representantes. Diferentemente da forma tradicional e conservadora de se perceber e entender o passado, a História Cultural leva em consideração diversos objetos históricos, tais como a cultura popular além da cultura letrada, as representações e práticas discursivas e sociais, assim como sua recepção. Enfim, trata de aspectos de uma história da cultura que não limita tal termo à produção literária e artística oficialmente reconhecida como erudita.

A História Cultural, segundo Chartier (2002), tem como objetivo principal identificar como, em diferentes lugares e momentos, uma determinada realidade foi pensada, construída e interpretada. Isso é devido ao fato de que as representações do mundo social são determinadas pelos interesses de um grupo, perpassando pela relação do discurso e seu 
proferidor. O discurso nunca é neutro, ao contrário, promove representações diversas, é percebido de determinadas maneiras e produz determinadas práticas (sociais, políticas, etc.). Assim, se as representações são diversas e subjetivas, é questionável como a História e as sociedades podem ser reconstruídas e contadas apenas com base em estruturas objetivas, como documentos seriados, textos e obras oficiais.

Barros (2005) lembra que "[...] qualquer objeto material produzido pelo homem faz também parte da cultura - da cultura material [...]” (p. 127). Por isso, a História Cultural engloba, como parte da cultura, os objetos da cultura material e os materiais provindos da cultura popular; engloba, além da linguagem, as representações, as práticas e os sujeitos (produtores e receptores).

Mas afinal, o que é cultura? Uma perspectiva de compreensão desse termo polissêmico é a de que cultura abrange as práticas e costumes, criações e saberes humanos (comida, música, roupa, festas, etc.). Nascemos imersos na cultura, que é plural. Nessa visão antropológica, ela representa tudo o que o homem produz, sendo ele próprio produto disso. Nas palavras de Geertz (1989), "[...] o homem é um animal amarrado a teias de significados que ele mesmo teceu, [...] sendo [a cultura] essas teias e a sua análise [...]” (p. 15).

Acerca desses conceitos, projetados em uma esfera educacional, Juliá (2001) complementa que "[...] o colégio não é somente um lugar de aprendizagem de saberes, mas também é um lugar de inculcação de comportamento e de habitus que exige uma ciência de governo transcendendo e dirigindo, segundo sua própria finalidade [...]” (p. 22), ou seja, não é um lugar apenas de transmissão cultural, de saberes pré-elaborados externamente; é também lugar de produção cultural, de construção de saberes e práticas e, muitas vezes, de convivência de grupos sociais distintos. Sendo assim, como objeto de estudo, a instituição escolar é um local que fornece indícios para melhor compreendermos o passado.

Taborda de Oliveira (2017) colabora ao referir que: 
[...] compreendemos que nada é neutro, inocente ou natural no processo de definição daqueles conhecimentos legitimados como dignos de serem transmitidos nas escolas, sejam científicos, artísticos, linguísticos ou quaisquer outros. Cada sociedade definirá nos seus próprios termos o que pretende da escola e produzirá as condições para transmitir alguns saberes em detrimento de outros. (TABORDA DE OLIVEIRA, 2017, p. 4).

De tudo o que foi exposto, podemos elencar certas questões acerca da escola e dos currículos: Por que determinadas disciplinas e respectivos conteúdos constam nos currículos? Por que aprendemos certos conteúdos e de determinadas formas?

\section{Cultura escolar e disciplinas escolares}

Para responder os questionamentos relacionados às instituições escolares e seus currículos, comecemos por considerar que cada estabelecimento de ensino tem sua própria cultura, com características próprias, as quais podem ser mais sutis ou mais notórias. Podemos dizer que não há duas instituições exatamente iguais, muito embora nelas possam ser encontradas semelhanças. Frago (2001) afirma que as diferenças são mais notáveis quando são comparadas as culturas de instituições de níveis educacionais diferentes. O motivo de tais diferenças dá-se pelo fato de que professores, alunos, familiares, pessoal administrativo e de serviços têm interesses, mentalidades e representações diferentes, gerando práticas e culturas diferentes.

Chervel (1990) estimula a capacidade da escola de produzir cultura, uma cultura específica, original, produtora e não apenas transmissora de saberes elaborados fora dela. A escola deve ser um lugar de constante movimento e produção. Para o autor, esse saber específico produzido pela instituição escolar tem efeitos sobre a cultura da sociedade. Em outras palavras, de acordo com o conceito de cultura exposto anteriormente, a cultura escolar se apropria das circunstâncias sociais ao mesmo tempo em que interfere na sociedade. 
De outro modo, Juliá (2001, p. 9) diz que “[...] a cultura escolar é descrita como um conjunto de normas que definem conhecimentos a ensinar e condutas a inculcar, e um conjunto de práticas que permitem a transmissão desses conhecimentos e a incorporação desses comportamentos [...]". O autor propõe três eixos para entender a cultura escolar como objeto histórico: sendo o primeiro focado nas normas e finalidades da escola; o segundo voltado à profissionalização do educador; e o terceiro direcionado aos conteúdos ensinados e modos de ensinar. Neste artigo, nos ateremos, principalmente, ao terceiro eixo, pois conteúdos, práticas e disciplinas escolares são inseparáveis das finalidades educativas. Veremos que, com o passar do tempo e local, redefine-se a finalidade e mudam-se os conteúdos e práticas.

Por meio da análise documental - neste caso, programas de ensino e legislação - é possível entender alguns aspectos estritamente vinculado às disciplinas escolares. Textos normativos e produções escritas escolares tornam-se documentos e fonte de pesquisa, cuja análise nos envia às práticas escolares, fornecendo indícios acerca da prática pedagógica. Embora não contemplados neste artigo, não seria demais lembrar-se de Vidal (2009) sobre a importância de explorar não só os conteúdos de livros e cadernos, mas a forma como era usado o espaço gráfico das páginas. Além de livros e cadernos, outras materialidades escolares, tais como suportes da escrita (lousas, quadros, etc.), objetos de escrita (giz, canetas, etc.), mobiliário (carteiras, relógios, etc.) também podem ser relevantes. Enfim, é importante que historiadores considerem tudo o que for parte da cultura, sendo evidente que, quanto mais fontes para pesquisa forem coletadas, melhor a reconstituição do passado.

Igualmente fazendo parte da história da educação, a história das disciplinas escolares passou a ser objeto de estudo a partir da década de 1970. Em relação ao termo disciplina escolar, Chervel (1990) indica a utilização dessa terminologia pela escola somente a partir da Primeira Guerra Mundial para designar os conteúdos de ensino. O autor destaca que uma disciplina escolar comporta desde as práticas docentes em sala de aula, até as finalidades que 
a constituíram e o fenômeno de aculturação que ela determina, de modo que a escola forma não somente os indivíduos, mas também uma nova cultura. De forma semelhante a Frago (2001), que as considera produtos específicos da cultura escolar, Juliá (2001, p. 33) acrescenta que “[...] não são nem uma vulgarização, nem uma adaptação das ciências de referência, mas um produto específico da escola [...]”".

A história das disciplinas escolares busca compreender o que ocorre no espaço escolar por meio das práticas de ensino realizadas na sala de aula e por meio dos objetivos que levaram a constituição das disciplinas, consideradas a "caixa-preta" da escola. Para Chervel (1990), é tarefa da história das disciplinas escolares identificar, classificar e organizar as finalidades que uma disciplina assume em determinada época, que podem ser de ordem religiosa, sóciopolítica, psicológica, cultural, entre outras. No entanto, o autor afirma que grande parte das finalidades impostas à escola está por ser desvelada.

Assim sendo, cabe ao historiador, num primeiro momento, ater-se à disciplina, ou seja, ao que está explícito nos programas, nos planos de estudos, nos livros, para, só depois, se possível, alcançar as práticas concretas. Para diferenciar suas finalidades, o autor diz ser necessário responder à seguinte pergunta: “[...] por que a escola ensina o que ensina?” (CHERVEL, 1990, p. 190). Segundo o autor, a tarefa essencial de quem quer estudar a história de uma disciplina é descrever detalhadamente o ensino efetivado, as mudanças didáticas, as razões de estas ocorrerem e a coerência dos procedimentos adotados para estabelecer a relação entre o ensino e suas finalidades.

Assim, na sequência, apresentamos sinteticamente a trajetória da disciplina da língua inglesa, dando ênfase aos acontecimentos político-históricos que influenciaram seu estabelecimento nas instituições escolares.

Antes, porém, importa destacar com base em Bourdieu (2006) que uma trajetória, seja de um sujeito, ou seja de uma disciplina como a Língua Inglesa, não se constitui como algo linear; na verdade, comporta avanços e recuos, comporta distintas posições - ora mais, ora 
menos relevantes - segundo razões que explicam seu movimento. Não podemos descurar também do fato de que, em se tratando de uma disciplina escolar, a posição ocupada tem a ver com interesses sociais, políticos e econômicos de grupos que forjam tanto a sua importância, o seu lugar social, quanto a sua retirada de cena.

\section{Disciplina da Língua Inglesa no Brasil: aspectos de uma trajetória}

Muitos podem ser os motivos para a inclusão e a consolidação de uma disciplina nos currículos escolares. Para entendermos essa inclusão (ou até sua exclusão), devemos analisar o contexto. Como referido, a escola não é apenas “[...] agente de transmissão de saberes elaborados fora dela [...]" (CHERVEL, 1990, p. 180), logo, os conteúdos escolares não são vulgarizações, simplificações ou adaptações de saberes eruditos. É preciso ter em conta a gênese, a função e o funcionamento, ou seja, quais conhecimentos foram pretensamente produzidos e veiculados por meio do ensino de certas disciplinas e os dispositivos escolares que lhe deram sustentação - como o livro didático, por exemplo.

A língua inglesa é uma disciplina escolar que tem feito parte da formação daqueles que passaram pela escola brasileira. Como qualquer disciplina escolar, ela não foi inserida arbitrariamente nos programas e currículos escolares. Para entendê-la, apresentaremos um breve panorama dessa disciplina no Brasil, recorrendo aos trabalhos dos autores Oliveira (1999), Casimiro (2005), Melo (2014), Lima (2008), Santos (2011), Quevedo-Camargo e Silva (2017) e Leffa (1988).

Em 1808, D. João VI veio de Portugal para o Rio de Janeiro em navios ingleses ${ }^{2}$ disposto a inserir no ensino brasileiro as ideias francesas do liberalismo enciclopedista. No entanto, nesse período, foram criados estabelecimentos comerciais ingleses no Brasil que, ao ofertar emprego, exigiam o domínio da língua inglesa. Devido a esse tipo de exigência, foi criada a cadeira de língua inglesa no país, juntamente à francesa. Assim, o ensino formal da 
língua inglesa no Brasil teve início com o decreto de 22 de junho de $1809^{3}$ - até então, o grego e o latim eram as línguas estrangeiras ensinadas na escola. As línguas francesa e inglesa passaram a ser disciplinas obrigatórias no currículo escolar brasileiro, visando aumentar a prosperidade, já que Portugal mantinha relações com a Inglaterra e a França (OLIVEIRA, 1999).

Nas aulas, os professores ${ }^{4}$ usavam o Método Clássico ou Gramática-Tradução ${ }^{5}$, que era o único método de ensino de línguas estrangeiras de que se dispunha na época. Nele, é sugerido que "os alunos deveriam não apenas falar e escrever as respectivas línguas, mas também conhecer o seu 'gênio', 'elegância' e ‘estilo' [...] o que mostra que o interesse pelas novas disciplinas revestia-se de um caráter cultural e literário [...]” (OLIVEIRA, 1999, p. 26), além da utilidade prática.

Apesar desse impulso inicial, somente o ensino de francês - língua então considerada universal - prosperou, enquanto que o ensino de inglês

restringiu-se aos seus objetivos mais imediatos, já que o seu conhecimento, não sendo exigido para o ingresso nas academias - portanto desnecessário ao currículo dos estudos secundários -, justificava-se apenas pelo aumento do tráfico e das relações comerciais da nação portuguesa com a inglesa, constituindo assim uma disciplina complementar aos estudos primários. (OLIVEIRA, 1999, p. 29).

No ano de 1837, com a criação do Colégio Pedro II no Rio de Janeiro, a língua inglesa foi incluída nos programas de ensino junto do latim e do francês; todavia ainda como opcional para os exames preparatórios das academias. Casimiro (2005) descreve que, em 1850, a Língua Inglesa era ensinada por meio de trechos selecionados em livros de literatura, ou seja, eram escolhidas páginas das obras para serem analisadas. Em 1855, um novo regulamento, tomando como modelo os liceus franceses, dividiu os estudos em duas etapas (uma delas de 4 anos, incluindo o estudo de inglês nos $2^{\circ}, 3^{\circ}$ e $4^{\circ}$ anos), ambas devendo ser cursadas para obtenção do título de Bacharel em Letras. A reforma do Ministro Souza Ramos, de 1862, 
decretou que o inglês, antes ensinado a partir do $2^{\circ}$ ano, passasse a ser ensinado a partir do $3^{\circ}$ ano (OLIVEIRA, 1999).

No ano de 1868, a reforma do Conselheiro Paulino de Souza interferiu no plano de estudos do Colégio Pedro II, e o inglês, então ensinado do quarto ao sétimo ano, perdeu sua finalidade puramente prática ao adotar "leitura, análise, composição e recitação" no 6 o ano e "história da língua, leitura, tradução e apreciação literária dos clássicos" no $7^{\circ}$ ano (OLIVEIRA, 1999).

Ainda, mantendo o caráter humanista da reforma anterior, em 1876, com a reforma do Ministro Cunha Figueiredo, esse ensino passou a contemplar “[...] gramática, temas, versão de prosadores e poetas ingleses e portugueses gradualmente difíceis e conversação [...]" (OLIVEIRA, 1999, p. 54). Sobre sua carga horária, a Reforma de 1879 (do Ministro Leôncio de Carvalho) propôs que a disciplina passasse a ser lecionada no terceiro e quarto anos. Importante notar que os professores e alunos ainda não contavam com livros didáticos para orientar seus estudos. A reforma seguinte, do Ministro Francisco Inácio Marcondes, restringiu o ensino da língua ao quarto e ao quinto anos.

Oliveira (1999) destaca que, após a proclamação da República, em 1890, tentou-se com a reforma educacional do Ministro Benjamim Constant, imprimir um teor enciclopédico nos cursos secundários, visando mudar o currículo humanista para o científico - parcialmente também devido ao descaso evidente em relação às línguas vivas estrangeiras e suas literaturas. Em 1892, o inglês, deixou de ser obrigatório no Ginásio e passou a ser oferecido como optativo, junto ao alemão, do $3^{\circ}$ ao $5^{\circ}$ ano, com caráter prático, como anteriormente às últimas reformas (CASIMIRO, 2005). Tal situação foi ligeiramente modificada quando, em 1898, a reforma do Ministro Amaro Cavalcanti propôs o estudo das línguas, ainda optativas, ensinadas do primeiro ao sétimo ano, recuperando a abordagem literária (CASIMIRO, 2005).

No século XX, as reformas do ensino da língua inglesa não foram interrompidas, algumas trazendo retrocessos, como a do Ministro Epitácio Pessoa, de 1901, que retirou o 
tratamento literário recém-adquirido, para retomar seu aspecto pragmático, que permaneceu após as reformas seguintes de 1911, do Ministro Rivadávia Correia e de 1915 do Ministro Carlos Maximiliano. Em 1931, com a reforma de Francisco Campos, houve mudança na estrutura do ensino visando adaptar o sistema de ensino à nova realidade do país: nacionalização e modernização. Essa Reforma ${ }^{6}$ incorporou mudanças no conteúdo e na metodologia do ensino de línguas estrangeiras: por exemplo, aumentou a ênfase dada às línguas modernas, diminuindo a carga horária do latim, além de reforçar seu caráter cultural e literário (OLIVEIRA, 1999). Também, adotou o Método Direto para o ensino de línguas estrangeiras. Essa nova prescrição, previa aulas ministradas na própria língua estrangeira. Pioneiro nas inovações, o Colégio Pedro II adotou este novo método e, no mesmo ano da Reforma, começou a praticá-lo em sala de aula.

Além disso, na década de 1930 surgiram os cursos livres de inglês no país. Em 1934 e 1935, foram fundadas, respectivamente, a Sociedade Brasileira de Cultura Inglesa do Rio de Janeiro e a Sociedade Brasileira de Cultura Inglesa de São Paulo, para difundir a língua, pensamentos, e cultura britânicos no Brasil. Em 1938, também em São Paulo, foi criado, com o apoio do consulado norte-americano, o primeiro instituto binacional: o Instituto Universitário BrasilEstados Unidos, posteriormente nomeado União Cultural Brasil-Estados Unidos (LIMA, 2008).

Com a reforma Capanema e a promulgação a Lei Orgânica do Ensino Secundário, em 1942, ocorreu nova mudança instituindo o primeiro ciclo (ginasial, de quatro anos) e o segundo ciclo (de três anos) subdividido em "clássico" e "científico". Sobre as aulas de línguas, "o inglês, no curso ginasial, era ensinado da segunda à quarta série, sendo optativo no curso clássico e figurando na primeira e segunda séries do científico [...]" (OLIVEIRA, 1999, p. 83). O programa contemplava sintaxe e história da literatura inglesa e norte americana. A carga horária das humanidades e línguas estrangeiras foi sendo reduzida de forma gradual, devido a maior importância dada às ciências. 
A pesquisa de Oliveira (1999) lembra que, em 1951, mudanças no currículo brasileiro ocorreram por conta do reconhecimento dos governantes acerca de sua inadequação para o momento, dado sua tradição livresca, o que requeria uma simplificação dos programas das diversas disciplinas do curso secundário, entre elas o inglês, incluindo a supressão do estudo de história da literatura inglesa.

Além dessa pesquisa, Casimiro (2005) também desenvolveu análise da disciplina escolar inglês em período semelhante, 1938 a 1958, focando nos livros didáticos utilizados no Colégio Pedro II do Rio de Janeiro, além de analisar os programas de ensino dessa disciplina. A autora informa que nos livros didáticos utilizados no Colégio Pedro II, de 1930 até 1960, predominava o Método Direto, que expunha “[...] realmente o teor da ideologia da classe detentora do poder, da inculcação de valores morais, normas, padrões, cultura provenientes, sobretudo, da civilização norte americana [...]" (CASIMIRO, 2005, p. 115). Esse aspecto em articulação com os conteúdos nos permite também saber sobre as finalidades (CHERVEL, 1990) dessa disciplina, concomitantemente ao entendimento de distintas abordagens sob as quais essa língua tem sido ensinada.

Segundo a autora, este método sofreu mudanças de nome ${ }^{8}$, mas seus objetivos fundamentais permaneceram:

Ler, escrever, falar e ouvir o idioma, a fim de que os alunos manifestem seu pensamento; dominem as estruturas gramaticais básicas da língua inglesa de modo gradativo; dominem um vocabulário básico que permita uma comunicação satisfatória em diferentes situações; leiam textos com entonação e pronúncia corretas; compreendam a importância do Inglês como instrumento de comunicação universal; ampliem seu universo, entrando em contato com a cultura e a civilização de outros países que falam a língua inglesa; aprendam uma língua estrangeira de forma viva, dinâmica e enriquecedora; desenvolvam as habilidades básicas na língua alvo, por meio da observação, da reflexão, do reconhecimento e da crítica dos aspectos linguístico-culturais, preparando-se para a formação consciente e responsável, como cidadãos de uma coletividade em constante evolução e transformação. (CASIMIRO, 2005, p. 120). 
Além das variações dos métodos de ensino, renovados conforme a pedagogia em voga, as sucessivas reformas do sistema educacional brasileiro, como pôde ser visto, têm ora negligenciado, ora tratado indevidamente o ensino de língua inglesa, chegando a ser até mesmo excluído da grade curricular obrigatória.

Em 1961, a Lei de Diretrizes e Bases (LDB) no 4.024 mudou a organização do ensino para primário, ginasial e colegial. Este último englobava o secundário, o normal e o técnico (comercial, industrial e agrícola). Quanto ao ensino de língua estrangeira moderna, essa lei estabeleceu obrigatoriedade parcial no $1^{\circ}$ ciclo, e apenas recomendava a inclusão da língua no $2^{\circ}$ ciclo conforme as condições de cada estabelecimento de ministrá-la com eficiência, não prevendo um método de ensino.

Curioso que essa LDB tenha retirado a obrigatoriedade do ensino da língua inglesa, deixando aos cuidados dos estados sua inclusão ou exclusão dos currículos, pois, após a Segunda Guerra Mundial, foi intensificada a relação econômica e cultural brasileira e norteamericana.

No entanto, o período de 1964 a 1985 tem importância na história brasileira por diversos motivos. Foi o período de regime ditatorial instaurado por meio de um golpe civil militar. Militares ocuparam a Presidência da República, os cargos administrativos e políticas ministeriais (economia, educação, cultura, esporte, etc.). Entre as medidas tomadas, estão os vários acordos assinados entre os governos do Brasil e dos EUA com a finalidade de impulsionar as relações entre os dois países. Um dos acordos firmados dizia respeito à educação.

Em junho de 1965 foi firmado um primeiro acordo sigiloso, que se tornou público em novembro de 1966, entre o Ministério da Educação e Cultura (MEC) e a Agência dos Estados Unidos para o Desenvolvimento Internacional (USAID - sigla em inglês), o qual desconsiderava as conquistas iniciadas em 1961 acerca da educação brasileira. Tratava-se de 
um acordo para reformar o ensino superior em conformidade com os padrões americanos cuja implementação ocorreu com a Lei no $5.540 / 68$.

Cunha (1991, p. 26) afirma que “[...] os acordos MEC-USAID cobriram todo o espectro da educação nacional, isto é, o ensino primário, médio e superior [...]”. Os técnicos norteamericanos, responsáveis pela implantação do programa, influenciaram a reforma da educação pública, atingindo todos os níveis de ensino.

Com a Lei no 5.691/71, houve a reorganização do ensino, com a redução de 12 anos para 11 - sendo oito anos de $1^{\circ}$ grau (fusão do primário e do ginásio) e três anos de $2^{\circ}$ grau (colegial científico ou clássico). Além disso, o curso universitário passou a ser denominado terceiro grau. Cunha (1991, p. 56) também refere que “[...] a ideia de acabar com os cursos clássico e científico, que só preparavam para vestibulares, nasceu da preocupação de conter a procura de vagas nos cursos superiores [...]", já que a partir dos anos 1940 vinha crescendo a procura pelos cursos superiores no país, o que não era interessante para o novo projeto econômico brasileiro.

Além disso, as escolas técnicas industriais passaram a representar o novo modelo de ensino, em que era oferecido um $2^{\circ}$ grau profissionalizante. Desse modo, a escola e a universidade passaram a ter a função de formar funcionários para a indústria de acordo com as funções requeridas nas linhas de montagens.

A redução dos anos escolares e o foco profissionalizante acarretaram em significativa redução na carga horária de Língua Estrangeira, além do fato de que tal inclusão era, então, optativa por cada um dos estabelecimentos escolares. Assim, muitas escolas eliminaram suas aulas no $1^{\circ}$ grau e reduziram a carga horária no $2^{\circ}$ grau para até uma hora semanal. Além disso, o ensino de inglês, mais uma vez sofreu modificações em sua metodologia, sendo adotada a Abordagem Comunicativa, em que a língua é pensada como conjunto de eventos comunicativos, com ênfase em sua semântica, ou seja, o conhecimento da língua para fins de comunicação. 
Com a LDB 9394/96 e reorganização do ensino em Educação Básica (Ensino Fundamental e Médio) e Superior foi reforçada a necessidade do ensino de, pelo menos, uma língua estrangeira no ensino fundamental, cuja escolha ficaria a cargo da comunidade escolar. No ensino médio foi estabelecida a obrigatoriedade de uma língua estrangeira moderna, sendo possível a oferta de uma segunda língua optativa, de acordo com as condições da instituição.

Em 1999, os Parâmetros Curriculares Nacionais (PCNs), em relação ao ensino fundamental, afirmam o foco na leitura, em detrimento da habilidade oral, justificado pela função social das línguas estrangeiras no país, e também, devido às condições existentes, como o fato de ser pequena a parcela da população brasileira que tem a oportunidade de usar línguas estrangeiras na comunicação oral, tanto dentro como fora do país (BRASIL, 1998). Além disso, devido ao fraco ensino das quatro habilidades comunicativas, admitiu-se as condições precárias da sala de aula da maioria das escolas brasileiras, bem como a carga horária reduzida, classes superlotadas, formação precária do corpo docente e do material didático - reduzido a giz e livro didático - como elementos influentes na ineficácia das aulas. No entanto, os PCNs do ensino médio sugerem que o ensino de línguas estrangeiras deveria enfatizar o desenvolvimento das quatro habilidades comunicativas, proporcionando a aquisição do domínio integral da língua estrangeira. Quanto a isso, Santos ironiza:

Confrontando-se os dois textos, tem-se a impressão de que tratam do ensino de línguas estrangeiras em dois países distintos. Um com condições para viabilizar um ensino comunicativo de línguas estrangeiras, no qual a competência comunicativa é relevante, e outro exatamente o oposto. (SANTOS, 2011, p. 2).

O documento também realça a importância da língua inglesa na vida profissional dos cidadãos. Porém, vinte anos depois de sua publicação, as escolas continuam sem recursos, com as salas de aula numerosas, professores sem formação específica, materiais didáticos inapropriados e o ensino de inglês defasado; o que não proporciona aos alunos o domínio das habilidades comunicativas básicas para atingirem propósitos profissionais elementares. 
$\mathrm{Na}$ tentativa de resolver essa questão, foi instituída a Lei $\mathrm{n}^{\circ} 13.415$, de 16 de fevereiro de 2017, que imprimiu a obrigatoriedade do inglês no currículo do ensino fundamental a partir do sexto ano, não mais deixando a livre opção de uma língua estrangeira moderna para a comunidade escolar.

$\mathrm{Na}$ prática, tanto as aulas nas escolas privadas de ensino fundamental e médio, quanto as públicas, fazem do antigo método focado em memorização e tradução, sua forma de conduzir o ensino. Santos (2011) esclarece que nas escolas privadas:

[...] o ensino de língua inglesa tem ficado restrito à explicação de regras gramaticais, a exploração de textos curtos não complexos e ao treinamento intensivo para resolução de questões de múltipla escolha, que no máximo, permitem resultados medianos nos processos seletivos de acesso ao ensino superior. A proposta nas escolas públicas parece ser a mesma, mas na prática, os resultados são ainda mais modestos. Pesquisas revelam que o ensino da língua inglesa na maioria das escolas públicas está limitado à apresentação das regras gramaticais mais básicas, exemplificadas com frases curtas e descontextualizadas, treinadas em exercícios escritos de repetição e de substituição típicos do audiolingualismo. (SANTOS, 2011, p. 3).

\section{Considerações Finais}

Cremos que, por meio dos apontamentos apresentados, seja possível que tenhamos uma noção da trajetória da língua inglesa no Brasil, desde o período imperial. Vimos que com maior ou menor importância, ela tem feito parte da cultura escolar brasileira no âmbito das práticas culturais desenvolvidas no Brasil ao longo do tempo.

Nessa busca por entender a posição da língua inglesa nos programas de ensino e currículo das escolas brasileiras, foi possível perceber a motivação de sua inserção e o lugar que tem ocupado no decorrer da história, o que ficou expresso pelo fato de a disciplina de língua inglesa, por vezes, não ter recebido muita importância, ao não ser incluída entre as disciplinas obrigatórias. Enquanto por outras, foi considerada tão importante quanto qualquer 
disciplina integrante ao currículo, fato que nos informa sobre a não linearidade de sua trajetória.

Pode-se constatar, lembremos, que o ensino da língua inglesa, como disciplina das escolas brasileiras, teve início em 1809, visando, junto ao ensino da língua francesa, às relações comerciais que Portugal tinha com a França e a Inglaterra. Isso significa que tal ensino tinha o objetivo de preparar alunos a tornarem-se profissionais capazes de comunicarem-se nessas línguas. Naquela época, o único método de ensino de línguas estrangeiras era o Método Clássico ou Gramática-tradução; como o próprio nome define, nas aulas os alunos deveriam aprender gramática e traduzir textos.

Também vimos que apesar da crescente importância do inglês para o mercado de trabalho, o francês ainda era considerado a língua franca, universal, o que resultou, no início do século XIX, no idioma inglês ainda como uma disciplina complementar aos estudos primários, e seu conhecimento ainda não era exigido para o ingresso nas academias do Império, diferente do francês. Foi somente a partir de 1831 que a língua inglesa começou a ser exigida nos exames de admissão às faculdades de direito, o que levou a inclusão do inglês no currículo oficial das escolas destinadas a esse tipo de instrução, em 1837. Todavia, visando o preparo para os cursos superiores e para o Exame de Madureza - como é o vestibular hoje, mantinham-se as finalidades exclusivamente práticas e o mesmo método de ensino.

Tal situação mudou ligeiramente com a reforma do ministro Francisco Campos, de 1931, o qual especificou os objetivos, conteúdo e metodologia do ensino de cada disciplina do então chamado "curso fundamental". O ensino das línguas vivas estrangeiras passou a contar com o Método Direto intuitivo, cuja proposta indicava a língua estrangeira a ser ensinada no próprio idioma estrangeiro.

Outro fato contundente é que, desde o início, tentou-se inserir o estudo da literatura inglesa no ensino de língua inglesa, porém esta manteve-se como uma matéria isolada, ou 
simples ramificação até 1951, quando foi suprimida do programa de inglês a fim de simplificar-se os programas de várias disciplinas.

Por fim, por meio dessa exposição da trajetória da língua inglesa como disciplina nas escolas brasileiras, pudemos observar que o ensino da língua inglesa, desde o início, com caráter utilitário passando por momentos em que foi agregado seu aspecto cultural, sempre se justificou pelos projetos político, econômico e social do país. Devido à evidente aproximação da política à educação, que afeta a organização do currículo, acreditamos que a história das disciplinas é importante para compreendermos parcela da História da Educação. 


\section{Notas}

${ }^{1} \mathrm{O}$ presente artigo tem seu conteúdo extraído de uma dissertação de mestrado.

${ }^{2}$ Lima (2008) considera que o primeiro contato do Brasil com a língua inglesa pode ter ocorrido por volta de 1530, quando William Hawkins, um aventureiro inglês, traficante de escravos, desembarcou na costa brasileira, abordando os lusitanos e os nativos.

${ }^{3}$ Há divergências quanto à factual inserção da disciplina nas instituições de ensino: alguns consideram que foi a partir desse decreto, outros consideram sua inserção em um período um pouco mais tardio, em 1838, com a inauguração do Colégio Pedro II, considerado o lócus no qual ela germinou e se propagou para os outros estabelecimentos de ensino secundário (CASIMIRO, 2005), ou ainda, 1855 como o início oficial do ensino de línguas estrangeiras no Brasil (QUEVEDO-CAMARGO e SILVA, 2017).

${ }^{4}$ Há registros de que o primeiro professor de inglês nomeado no Brasil, foi o padre irlandês Jean Joyce.

${ }^{5} \mathrm{~A}$ abordagem da gramática e tradução consiste numa metodologia que visa a tradução de texto da língua alvo para a materna. O foco está na leitura e na produção escrita, feitas de maneira mecânica. "Surgiu com o interesse pelas culturas grega e latina no Renascimento e continua sendo empregada até hoje” (LEFFA, 1988, p.4).

${ }^{6}$ Dividiu o ensino em dois cursos seriados, o fundamental (obrigatório para ingresso em escola superior, com duração de cinco anos sendo o inglês ministrado da segunda à quarta série) e o complementar (de dois anos, subdividido em pré-jurídico, pré-médico e pré-politécnico, dependendo da especialização que se pretendia seguir).

${ }^{7}$ Diferentemente do Método Clássico, nessa abordagem o ensino dá-se por meio da própria língua estrangeira, "[...] a língua materna nunca deve ser usada na sala de aula. A transmissão do significado dá-se através de gestos e gravuras, sem jamais recorrer à tradução [...]” (LEFFA, 1988, p.6). Apesar de nova nas escolas brasileiras, essa abordagem foi oficializada muito antes em outros países como Bélgica (1895), França (1902) e Alemanha (1902). ${ }^{8}$ Por exemplo, a Abordagem Audiolingual pode ser considerada uma reedição da Abordagem Direta, que enfatiza a língua oral e adota o processo de estímulo e resposta, sendo importante o reforço do professor às respostas certas. $\mathrm{O}$ audiolingualismo dominou o ensino de línguas a partir da Segunda Guerra Mundial, até o início da década de 1970. Apoiava-se não somente no livro didático, mas também em materiais auditivos e visuais como fitas, filmes etc.

\section{Referências}

BARROS, J. D. A história cultural e a contribuição de Roger Chartier. Diálogos, v. 9, n. 1, 2005, p. 125-141.

BITTENCOURT, C. M. F. Disciplinas escolares: história e pesquisa. In: OLIVEIRA, Marcus A. Taborda.; RANZI, Serlei. M. Fisher. (Org.) História das disciplinas escolares no Brasil: contribuições para o debate. Bragança: Ed. Univ. São Francisco, 2003. p. 9-39.

BOURDIEU, P. A Ilusão Biográfica. In: FERREIRA, Marieta de Morais e AMADO, Janaína (Orgs). Usos e Abusos da História Oral. Rio de Janeiro: Fundação Getúlio Vargas, 2006 
BRASIL, Ministério da Educação. Parâmetros Curriculares Nacionais: Ensino Fundamental, 1998.

BRASIL, Ministério da Educação. Parâmetros Curriculares Nacionais: Ensino Médio Brasileiro, 1999.

CASIMIRO, G. S. A língua inglesa no Brasil: contribuições para a história das disciplinas escolares. Campo Grande: Editora da Uniderp, 2005.

CHARTIER, R. A história cultural: entre práticas e representações. Trad. Maria Manuela Galhardo. Lisboa: Difusão Editora, 2002, p.13-28.

CHERVEL, A. História das disciplinas escolares: reflexões sobre um campo de pesquisa. Teoria \& Educação, Porto Alegre, v. 2, 1990, p. 177-229.

CUNHA, L. A; GOES, M. O Golpe na Educação. Rio de Janeiro: Jorge Zahar, 7ed. 1991. FARIA FILHO, L; GONÇALVES, I; VIDAL, D; PAULILO, A. A cultura escolar como categoria de análise e como campo de investigação na história da educação brasileira. Educação \& Pesquisa, 30 (1), 2004, p. 139-159.

FRAGO, A. V. Fracasan las reformas educativas? La respuesta de un historiador. In: Sociedade Brasileira de História da Educação (Org.). Educação no Brasil: história e historiografia. Campinas: Autores Associados, 2001, p. 21-52.

FRAGO, A. V. A História das Disciplinas Escolares. Revista Brasileira de História da Educação, n.18, set/dez, 2008, p.172-215.

GEERTZ, C. As interpretações das culturas. Rio de Janeiro: Editora Guanabara, p. 13-41, 1989.

JULIA, D. A cultura escolar como objeto histórico. Revista Brasileira de História da Educação, Campinas/SP, n. 1, p. 9-44, 2001.

LEFFA, V. J. Metodologia do ensino de línguas. In BOHN, Hilário; VANDRESEN, Paulino (orgs). Tópicos em lingüística aplicada: O ensino de línguas estrangeiras. Florianópolis: Ed. da UFSC, 1988, p. 211-236

LIMA. G. P. Breve Trajetória da Língua Inglesa e do Livro Didático de Inglês no Brasil. Anais: VII Seminário de Pesquisa em Ciências Humanas. Londrina, 2008. Disponível em: http://www.uel.br/eventos/sepech/sepech08/arqtxt/resumos-anais/GislainePLima.pdf. Acesso em: 21 de março de 2019 
MELO, T. S. R. Estereótipos de gênero em livros didáticos de inglês das décadas de 1960, 1970 e 1990: implicações na prática docente. Dissertação (Mestrado em Educação). Programa de PósGraduação em Educação Pontifícia Universidade Católica do Paraná, Curitiba, 2014

OLIVEIRA, L. E. M. de. A historiografia brasileira da literatura inglesa: uma história do ensino de inglês no Brasil (1809-1951). Dissertação (Mestrado em Linguística) Instituto de Estudos da Linguagem. Universidade Estadual de Campinas, Campinas, 1999.

QUEVEDO-CAMARGO, G; SILVA, G. O inglês na educação básica brasileira: sabemos sobre ontem; e quanto ao amanhã? Ensino e Tecnologia em Revista. Londrina, v. 1, n. 2, jul./dez. 2017, p. 258-271. Disponível em:

<https://periodicos.utfpr.edu.br/etr/article/view/7500>. Acesso em: 21 de março de 2019.

SANTOS, E. S. S. O Ensino da Língua Inglesa no Brasil. BABEL: Revista Eletrônica de Línguas e Literaturas Estrangeiras. v. 01, p. 01, 2011, p.39-46.

TABORDA DE OLIVEIRA, M. A. Os estudos históricos sobre o currículo e as disciplinas escolares: das preocupações com as práticas escolares para o mundo da pesquisa acadêmica. Pensar a Educação em Revista, v. 3, p. 3-41, 2017.

UPHOFF, D. A história dos Métodos de Ensino de Inglês no Brasil. In: BOLOGNINI, Carmen Zink (org). A língua inglesa na escola. Discurso e ensino. Campinas: Mercado de Letras, 2008, p. $9-15$.

VIDAL, D. G. Cultura e práticas escolares como objeto de pesquisa em História da Educação. In: ROCHA, Marlos Bessa Mendes da (org) Cultura e história da educação: intelectuais, legislação, cultura escolar e imprensa. Juiz de Fora: Editora UFJF, 2009, p. 103 - 110.

Recebido em 08 ago. 2019 / Aprovado em 18 nov. 2019

\section{Para referenciar este texto:}

BOCCA, Sofia. Língua inglesa no Brasil, reformas educativas e métodos de ensino: aspectos de uma trajetória disciplinar. Cadernos de Pós-graduação, São Paulo, v. 18, n. 2, p. 29-48, jul./dez. 2019. Disponível em: < https://doi.org/10.5585/cpg.v18n2.14594> 